\title{
Fertility outcomes following myomectomy in infertile patients at our centre: a retrospective analysis
}

\author{
Nidhi Goyal*, K. Jayakrishnan
}

\begin{abstract}
Department of Infertility and Reproductive Medicine, KJK Hospital and Fertility Research Centre,
\end{abstract} Thiruvananthapuram, Kerala, India

Received: 01 May 2020

Accepted: 13 May 2020

\author{
*Correspondence: \\ Dr. Nidhi Goyal, \\ E-mail: nidhi.goyal67@gmail.com
}

Copyright: (c) the author(s), publisher and licensee Medip Academy. This is an open-access article distributed under the terms of the Creative Commons Attribution Non-Commercial License, which permits unrestricted non-commercial use, distribution, and reproduction in any medium, provided the original work is properly cited.

\begin{abstract}
Background: Fibroids have been known to cause infertility due to multiple factors. However, the role of myomectomy in patients with intramural and subserosal fibroids has been a topic of debate. This study evaluates outcomes following myomectomy in patients seeking treatment for infertility at study centre.

Methods: This was hospital based retrospective study which evaluated 92 infertile patients who took treatment for infertility.

Results: A total $41.3 \%$ patients conceived within one year of myomectomy. Pregnancy rates were better in patients with intramural combined with submucous fibroids, age between 30 and 35 years, size of largest fibroid between 3 and $6 \mathrm{~cm}$ and when number of fibroids were between 3 and 6 and conception was maximum after ovulation induction. Conclusions: Pregnancy rates after myomectomy are better in young patients with large fibroids. Active management for infertility needs to be done after myomectomy.
\end{abstract}

Keywords: Fibroid, Infertility, Myomectomy, Pregnancy

\section{INTRODUCTION}

Fibroids are the most common benign tumors of women in reproductive age group. 5-10\% of infertile women may have fibroids, however fibroids being the sole cause of infertility occurs in $1-2.4 \%$ of cases. ${ }^{1,2}$ Fibroids have been known to cause infertility due to physical factors, altered uterine contractility and chronic inflammatory reaction. ${ }^{3-7}$ Submucous fibroids decrease fertility and removal increases fertility rates. Subserosal fibroids do not affect fertility but removing them increases fertility rate. Intramural fibroids may slightly decrease fertility, but removal does not increase fertility. ${ }^{8}$ The size of fibroid also plays a major role. Studies have shown that women with fibroids larger than $4 \mathrm{~cm}$ have poorer prognosis even after removal. ${ }^{9}$ Myomectomy is recommended for patients with unexplained infertility in the presence of fibroid. This study evaluates the fertility rates of infertile patients who were taking active treatment for infertility after undergoing myomectomy.

\section{METHODS}

The study was a hospital-based retrospective study carried out at KJK Hospital and Fertility Research Centre, Trivandrum. 92 patients seeking treatment for infertility from September 2015 to March 2018, and diagnosed to have fibroid uterus were included. There was a time interval of 6 months between diagnosis of fibroid and myomectomy, and during this interval patient took active treatment for infertility, including natural and ovulation induction cycles or Intrauterine Insemination (IUI). Each patient had a follow up period of 1 year. Following myomectomy, 2-3 cycles of ovulation induction followed by 3-4 cycles of intrauterine insemination were given. If the patient did not conceive, 
in-vitro fertilization (IVF) was done for the patient. The exclusion criteria included age greater than 38 years, patients with polycystic ovarian syndrome, moderate and severe endometriosis, adenomyosis, poor ovarian reserve, dense adhesions, male factor, gross tubal pathology, negative chromopertubation test on laparoscopy, previous history of myomectomy, medical conditions that may contribute to infertility, congenital uterine anomalies and patients lost in follow-up.

\section{Statistical analysis}

Data was collected and statistical analysis was done using SPSS IBM 23.0.0.0.

\section{RESULTS}

Majority of the study population (44.6\%) was between 30 and 35 years of age, had primary infertility $(66.3 \%)$ and suffered from infertility for 2-5 years (Table 1).

Table 1: Demographic characteristics of the study population.

\begin{tabular}{|ll|}
\hline Age (years) $\mathbf{N}(\%)$ & Infertility duration (years) \\
$\mathbf{N}(\%)$
\end{tabular}

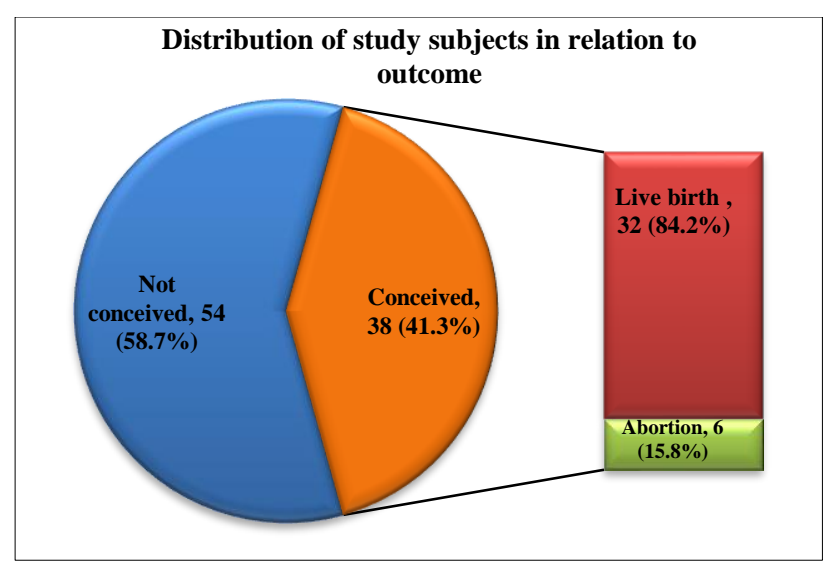

Figure 1: Conception after myomectomy.

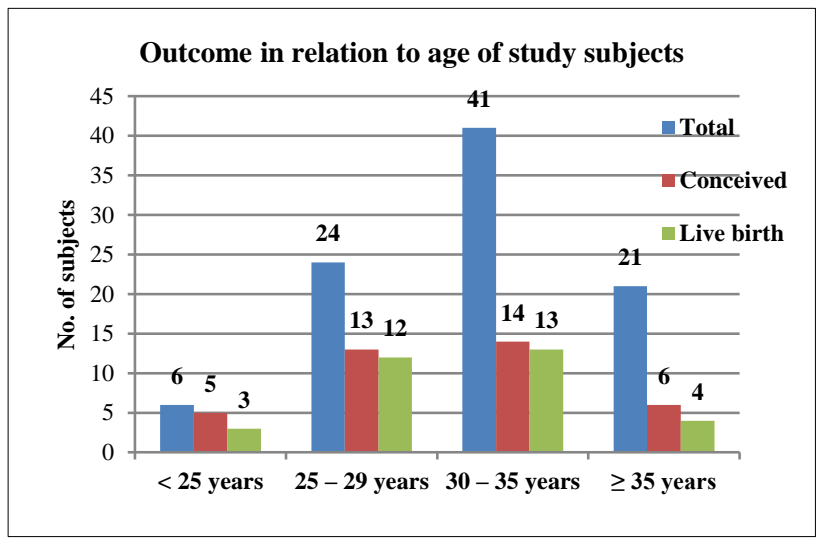

Figure 2: Age versus conception.

Table 2: Outcomes following myomectomy in relation to type of fibroid.

\begin{tabular}{|llllll|}
\hline Type of fibroid & $\begin{array}{l}\text { Total } \\
\text { subjects }\end{array}$ & $\mathbf{N}$ & Conceived & Live birth & N \\
\hline SMF only & 4 & 1 & $25 \%$ & 1 & $25 \%$ \\
\hline IMF only & 24 & 9 & $37.5 \%$ & 7 & $29.2 \%$ \\
\hline SSF only & 12 & 4 & $33.3 \%$ & 3 & $25 \%$ \\
\hline IMF + SMF & 4 & 3 & $75 \%$ & 3 & $75 \%$ \\
\hline IMF + SSF & 43 & 21 & $48.8 \%$ & 0 & $41.9 \%$ \\
\hline SMF + SSF & 2 & 0 & $0 \%$ & 0 & $0 \%$ \\
\hline IMF+SMF+SSF & 3 & 0 & $0 \%$ & 32 & $34.8 \%$ \\
\hline Total & 92 & 38 & $41.3 \%$ & 0.432 & \\
\hline p value & & 0.294 & & & $0 \%$ \\
\hline
\end{tabular}

A total $19.6 \%$ of the patients had distortion of the cavity and cavity was entered in $21(22.8 \%)$ patients. $85.7 \%$ had laparoscopic myomectomy, $4.3 \%$ had hysteroscopic resection, $8(8.7 \%)$ had combined laparoscopic and hysteroscopic resection and in 1 patient laparoscopy was converted to laparotomy. Other finding noted were adhesions, minimal and mild endometriosis, pelvic inflammatory disease, and hydrosalpinx. Major other factors such as dense adhesions and moderate and severe endometriosis were already excluded. 38 patients $(41.3 \%)$ conceived within one year of myomectomy (Figure 1) of which 32 resulted in live birth. Whereas, the conception rate of patients who conceived spontaneously at study centre within 1 year of diagnosis of infertility was $23.4 \%$. 28 had term live birth and 4 delivered before 37 weeks. There was no incidence of uterine rupture. The outcome 
was better in patients who were between 30 and 35 years of age and had infertility for 2 to 5 years of age (Figure 2, 3 ). Outcome was also better in patients who had intramural fibroid along with submucous fibroids (Table 2), largest size of fibroid between 3 and $6 \mathrm{~cm}$ and when the number of fibroids was between 3 and 6 (Figure 4, 5). Majority of the patients conceived after ovulation induction and only $7.9 \%$ conceived spontaneously.

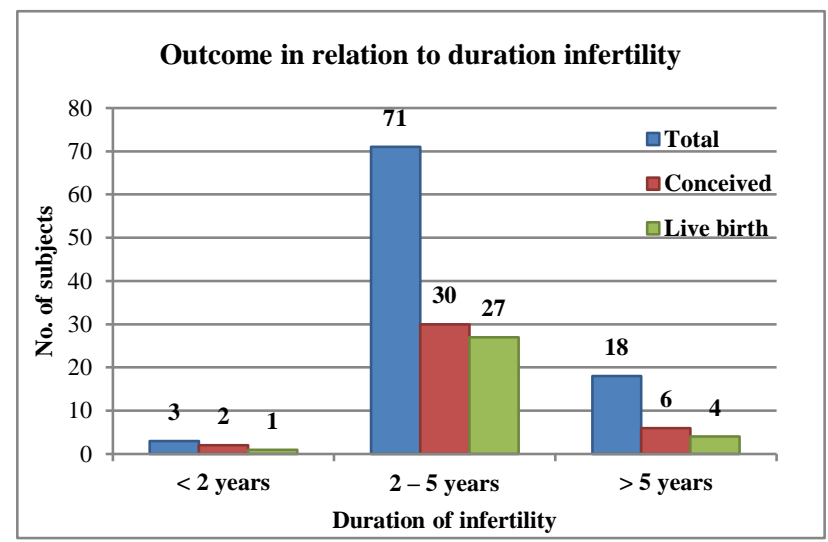

Figure 3: Duration of infertility versus conception.

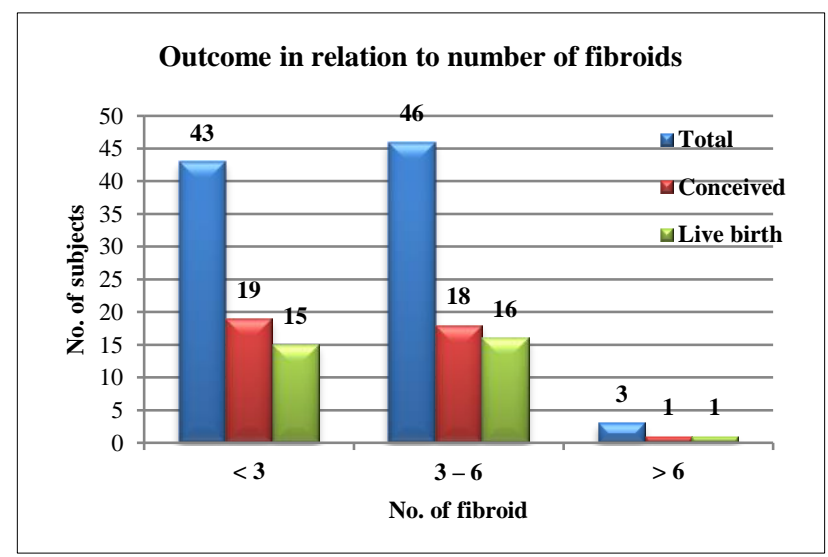

Figure 4: Number of fibroids versus pregnancy.

Table 3: Mode of conception after myomectomy. Majority of patients conceived after ovulation induction.

\begin{tabular}{|l|l|l|}
\hline Mode of conception & N & Percentage \\
\hline Natural & 3 & $7.9 \%$ \\
\hline IUI & 7 & $18.4 \%$ \\
\hline IVF & 6 & $15.8 \%$ \\
\hline OI & 22 & $57.9 \%$ \\
\hline Total & 38 & $100 \%$ \\
\hline
\end{tabular}

\section{DISCUSSION}

The overall pregnancy rate after myomectomy was $41.3 \%$ which better than some other studies due to meticulous surgical techniques and active management after surgery in the form of ovulation induction, IUI or IVF. ${ }^{10,11}$ The incidence of uterine rupture in a study is $5.4 \%$ in patients who have undergone myomectomy. ${ }^{12}$ However, the incidence in this case was nil due to better monitoring and patients were taken for elective cesarean in case there was a history of cavity opening at the time of surgery.

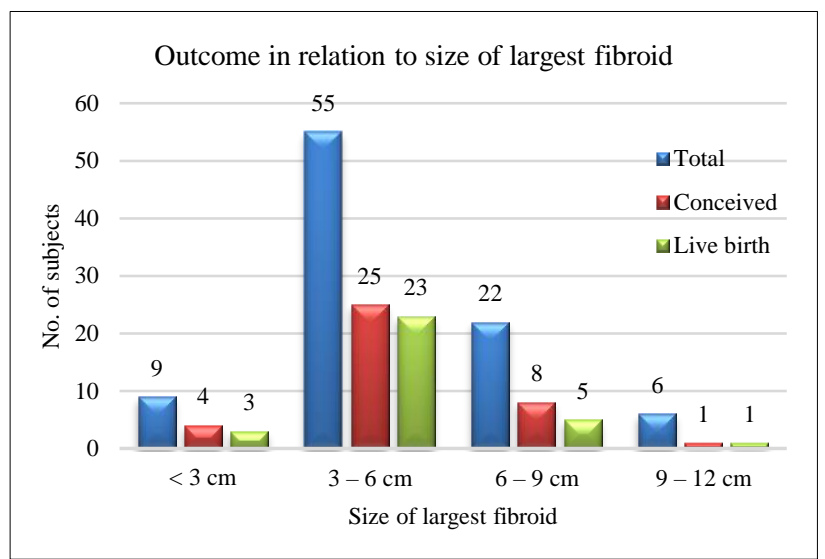

Figure 5: Size of largest fibroid versus pregnancy.

Pregnancy rate was $75 \%$ in patients with intramural and submucous fibroid combine and $25 \%$ in submucous fibroids alone. This is contrary to some other studies where subserosal fibroids alone had better pregnancy rates. $^{13,14}$ This can be attributed to smaller study population and other confounding factors which cannot be ruled out. Larger fibroids between 3 and $6 \mathrm{~cm}$ and multiple fibroids had better pregnancy rates which is in accordance with other studies. ${ }^{9}$ Majority of patients conceived after ovulation induction which shows that active management of infertility is required after myomectomy. However, randomized controlled studies on a larger scale are required to come to conclusions in Indian population.

\section{Funding: No funding sources \\ Conflict of interest: None declared \\ Ethical approval: Not required}

\section{REFERENCES}

1. Benecke C, Kruger TF, Siebert TI, Van der Merwe JP, Steyn DW. Effect of fibroids on fertility in patients undergoing assisted reproduction. A structured literature review. Gynecol Obstetric investigation. 2005;59(4):225-30.

2. Donnez J, Jadoul P. What are the implications of myomas on fertility? A need for a debate? Human reproduction (Oxford, England). 2002;17(6):142430.

3. Yang $\mathrm{CH}$, Chung PC, Tsai YC, Chuang LY. Endometrium characterization in connection with uterine contraction. IEEE Trans Nuclear Sci. 2001;48(4):1435-9.

4. Richards PA, Richards PD, Tiltman AJ. The ultrastructure of fibromyomatous myometrium and its relationship to infertility. Human Reprod Update. 1998;4(5):520-5. 
5. Rackow BW, Taylor HS. Submucosal uterine leiomyomas have a global effect on molecular determinants of endometrial receptivity. Fertil Steril. 2010;93(6):2027-34.

6. Kido A, Ascher SM, Hahn W, Kishimoto K, Kashitani N, Jha RC, et al. 3 T MRI uterine peristalsis: comparison of symptomatic fibroid patients versus controls. Clin Radiol. 2014;69(5):468-72.

7. Yoshino O, Nishii O, Osuga Y, Asada H, Okuda S, Orisaka M, et al. Myomectomy decreases abnormal uterine peristalsis and increases pregnancy rate. J Minimally Invas Gynecol. 2012;19(1):63-7.

8. Pritts EA, Parker WH, Olive DL. Fibroids and infertility: an updated systematic review of the evidence. Fertil Steril. 2009;91(4):1215-23.

9. Oliveira FG, Abdelmassih VG, Diamond MP, Dozortsev D, Melo NR, Abdelmassih R. Impact of subserosal and intramural uterine fibroids that do not distort the endometrial cavity on the outcome of in vitro fertilization-intracytoplasmic sperm injection. Fertil Steril. 2004;81(3):582-7.

10. Goldberg J, Pereira L. Pregnancy outcomes following treatment for fibroids: uterine fibroid embolization versus laparoscopic myomectomy. Curr Opinion Obstet Gynecol. 2006;18(4):402-6.

11. Dubuisson JB, Chapron C, Chavet X, Gregorakis SS. Fertility after laparoscopic myomectomy of large intramural myomas: preliminary results. Human reproduction (Oxford, England). 1996;11(3):518-22.

12. Roopnarinesingh S, Suratsingh J, Roopnarinesingh A. The obstetric outcome of patients with previous myomectomy or hysterotomy. The West Indian Med J. 1985;34(1):59-62.

13. Casini ML, Rossi F, Agostini R, Unfer V. Effects of the position of fibroids on fertility. Gynecol Endocrinol. 2006;22(2):106-9.

14. Metwally M, Cheong YC, Horne AW. Surgical treatment of fibroids for subfertility. The Cochrane Data Syst Rev. 2012;11:Cd003857.

Cite this article as: Goyal N, Jayakrishnan K. Fertility outcomes following myomectomy in infertile patients at our centre: a retrospective analysis. Int J Reprod Contracept Obstet Gynecol 2020;9:2249-52. 